\title{
Gastrointestinal kanama ile başvuran erişkin başlangıçlı Henoch-Schönlein vasküliti ve ankilozan spondilitli bir olgu
}

A case with adult-onset Henoch-Schönlein vasculitis presenting with gastrointestinal bleeding and ankylosing spondylitis

Mustafa BAŞAK ${ }^{1}$, Abdulsamet ERDEN ${ }^{1}$, Kadir BULUT ${ }^{1}$, Fatma AYKAŞ ${ }^{1}$, Hatice KARAMAN ${ }^{2}$, Ahmet KARAMAN

Kayseri Eğitim ve Araştırma Hastanesi ${ }^{1} I_{c ̧}$ Hastalıklan Kliniği, ${ }^{2}$ Patoloji Kliniği, ${ }^{3}$ Gastroenteroloji Kliniği, Kayseri

Henoch Schönlein purpurası histopatolojik olarak küçük damarların IgA baskın immunkompleks birikimi ile karakterize vaskülitidir. Purpurik deri döküntüsü, glomerulonefrit ve gastrointestinal sistem tutulumu hastalığın tipik klinik bulgularıdır. Hastaların büyük çoğunluğu 20 yaş altındadır Erişkinlerde daha nadiren görülür ve klinik prezentasyonu çocuklardan biraz farklıdır. Gastrointestinal bulgular erişkinlerde daha az siklıkta görülmektedir. Hastalığın bir başka özelliği; ailevi Akdeniz ateşi olan çocuklarda (130/1000) belirgin artmış sıklıkta gözlenmesidir. Bununla beraber Henoch-Schönlein purpurası ve seronegatif spondiloartropati birlikteliği nadir olarak bildirilmiştir. Biz gastrointestinal kanama ve purpurik deri döküntüsü ile prezente olan ve ilginç olarak beraberinde ankilozan spondilit tespit edilen bir olguyu bildiriyoruz.

Anahtar Kelimeler: Henoch-Schönlein purpurası, gastrointestinal kanama, ankilozan spondilit
Henoch-Schönlein purpura is characterized histopathologically by small vessel vasculitis with immunoglobulin A-dominant immune complex deposition. Purpuric skin rash, glomerulonephritis, and gastrointestinal tract involvement are typical clinical findings of the disease. The majority of patients are under 20 years of age. It is seen more rarely in adults, and the clinical presentation is somewhat different from that in children. Gastrointestinal symptoms are less frequent in children than in adults. Another feature of the disease, familial Mediterranean fever, is observed with significantly higher frequency in children (130/1000). Nevertheless, Henoch-Schönlein purpura and seronegative spondyloarthropathy has been reported as a rare combination. We report herein a case presenting with gastrointestinal bleeding and purpuric skin rash, in whom, interestingly, ankylosing spondylitis was also detected.

Keywords: Henoch-Schönlein purpura, gastrointestinal bleeding, ankylosing spondylitis

\section{GİRISS}

Henoch-Schönlein purpurası (HSP), çocuklarda en sık görülen sistemik vaskülittir. Non-trombositopenik purpura, artrit veya artralji, karın ağrısı, gastrointestinal kanama ve glomerülonefrit ile karakterizedir $(1,2)$. Küçük damarlarda, başlıca post kapiller venüllerde IgA dominant immundepositler bulunur (1). Gastrointestinal tutulum olguların yaklaşık yarısında görülse de nadir olgularda üst ya da alt gastrointestinal kanama ortaya çıkmaktadır $(2,3)$. Ankilozan spondilit, esas olarak sakroiliyak ve omurga gibi merkezi iskeleti, daha az sılıkta çevresel eklemleri tutan, ankiloz yapabilen, kronik seyirli, inflamatuvar ve multisistemik bir hastalıktır (4). Çoğunlukla 15-30 yaşlarında başlar. Hastaların yarısında gastrointestinal sistemde mikroskopik olarak inflamasyon saptanmasına rağmen klinik bulgu sadece \%5-10 hastada görülür (4).

\section{OLGU}

Yirmibir yaşında erkek hasta 3-4 hafta öncesinde ilk olarak ayaklarında başlayan daha sonra tüm vücuda yayılan dökün- tüler nedeniyle polikliniğimize başvurdu. 3 gün önce vaskulit ön tanısıyla cilt biyopsisi alınmış ve steroid başlanmış olan hasta 3 gündür devam eden makattan kan gelmesi ve karın ağrısı şikayetleri ile acil serviste değerlendirilerek gastrointestinal sistem (GIS) kanaması ön tanısıyla yatırıldı. Özellikle alt ekstremite eklemlerinde olmak üzere kalça ekleminde ağrı tarifleyen hastanın hikayesinde yaklaşık bir saat süren sabah sertliği mevcuttu. Fizik muayenede özellikle alt extremitelerde ayak bilekleri etrafinda yoğunlaşan bilateral yer yer üzeri kurutlu, yer yer büllöz özellik gösteren ekstremitelerin ekstensör yüzlerine dağılan kırmızı - kahverengi renginde purpurik döküntüler mevcuttu. Bu döküntüler azalarak üst ekstremiteler ve gövdeye de yayılmakta idi (Resim 1). Batın muayene ile hassas idi, ancak rebound ve defans saptanmadi. Lomber omurga hareketinin frontal ve sagittal düzlemde k1sitlıydı. Göğüs ekspansiyonu 2.5 cm'den azdı (4. Interkostal aralıktan). Laboratuvar incelemesinde nötrofil hakimiyetinde beyaz küre yüksekliği dışında (Beyaz küre:17800, nötrofil 


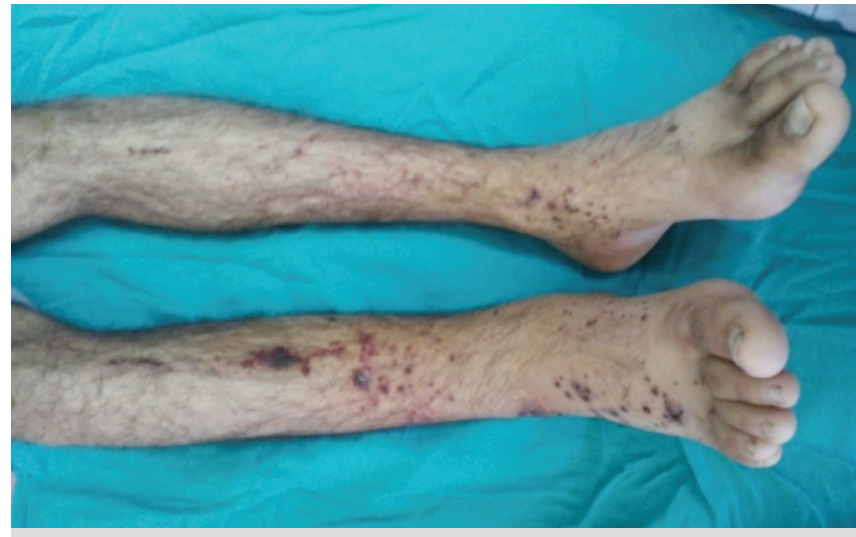

Resim 1. Alt ekstremitelerde belirgin palpabl purpuralar

oranı: \%83) patolojik bulguya rastlanmadı. Batın ultrasonografisi normal bulundu. AP pelvis grafisinde sol sakroiliyak eklem kapalı ve yer yer skleroz artışı mevcuttu (Resim 2). Alt GIS kanaması nedeniyle yapılan kolonoskopik girişimde; anal kanaldan başlayarak incelendiğinde splenik fleksuraya kadar mukoza diffüz eritemli ve ödemliydi. Yer yer ülserler izlendi. Subepitelyal yaygın 2-3 mm'lik peteşiler izlendi ve biyopsi alındı. Proksimale doğru lezyonların şiddetinde artma izlendi ve aktif kolit olarak değerlendirildi. Barsak biyopsisinde nonspesifik kolit olarak değerlendirildi. Cilt biyopsisinde ise dermal damarlar çevresinde IgA depozitleri ve granülosit infiltrasyonu, lökositoklastik vaskülit olarak saptandı. Hasta, HSP olarak değerlendirildi. Çekilen sakroiliyak magnetik rezonans (MR) sakroileit ile uyumlu idi. Hastada inflamatuvar tipte bel ağrısı, hareket kısitlılığı, sakroileti olması ve Schober testi pozitif olması üzerine ankilozan spondilit tanısı kondu. Hastaya metil-prednizolon $1 \mathrm{mg} / \mathrm{kg} /$ gün beraberinde esomeprazol $40 \mathrm{mg} / \mathrm{gün}$ başlandı. Tedavinin devamında cilt lezyonlarının gerilediği ve hastanın kliniğinin düzeldiği görüldü. Ankilozan spondilite yönelik salazoprin tedavisi eklendi. Kanaması olmayan, hareket kısıtlılığı azalan hastanın takiplerine devam edilmektedir.

\section{TARTIŞMA}

Henoch-Schönlein vasküliti bir immün kompleks vasküliti olarak kabul edilir ve en sık 5-7 yaş arası çocukları etkiler. Insidansı yaklaşık 20/100000'dir (2,3). Histopatolojik olarak deri ve diğer lezyonlarda nötrofil ağırlıklı damar iltihabı ve eşlik eden IgA baskın immunkompleks birikimi gözlenir (1). Olasılıkla henüz bilinmeyen bir antijenik uyarının IgA artışı ve alternatif kompleman sistemini aktifleyerek patogenezde rol oynadığı varsayılır (1). En sık tutulum yerleri cilt, eklemler, gastrointestinal sistem ve böbreklerdir $(1,2)$. Klasik Henoch-Schönlein tetradı: 1- Özellikle alt ekstremitelerde belirgin palpabl purpurik döküntü, 2- Artralji veya artrit, 3- Karın ağrısı, 4- Renal fonksiyonlarda bozulmadır (5). Alt ekstremitelerde belirgin palpabl purpura, özellikle eklem ve barsak

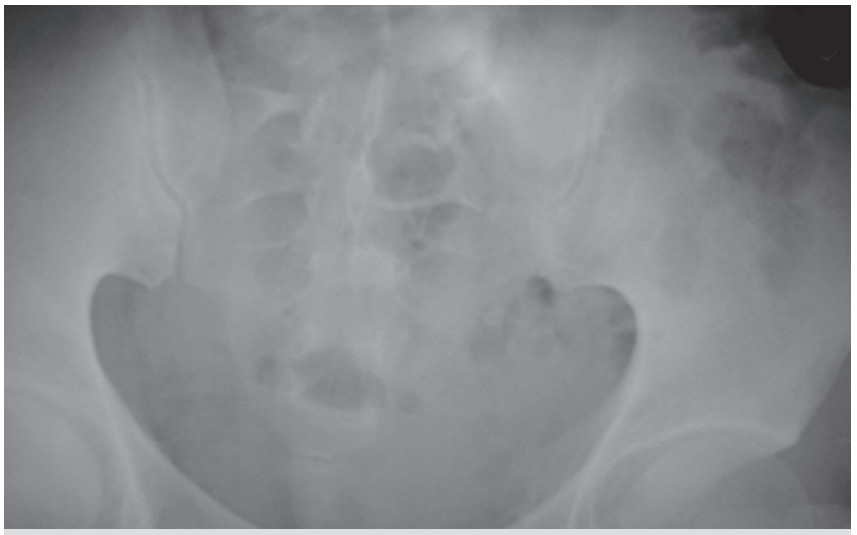

Resim 2. AP pelvis grafisi

yakınmalarının daha az gözlendiği (\%20) erişkin grupta en sık başlangıç bulgusudur (1). Barsak tutulumu özellikle çocuklarda yüksek oranda gözlenir (\%70) (1). Kolik tarzda karın ağrısı beraberinde bulantı, kusma, kanlı ve mukuslu ishal görülür (1-3,5). Gizli gastrointestinal kanama vakaların \%20 -30'unda bildirilse de masif gastrointestinal kanamalar \%12'sini teşkil etmektedir $(6,7)$. Blanco ve arkadaşlarının yaptığı çalışmada hastalığın başlangıcında erişkinlerde gastrointestinal ve renal tutulumun daha fazla görüldüğü saptanmıştır (8). Erişkinlerde en sık görülen gastrointestinal bulgular karın ağrısı (\%86), gaytada gizli kan pozitifliği (\%66) olmakla birlikte masif endoskopik veya cerrahi tedavi gerektirecek GIS kanamaları oldukça nadir görülmektedir $(9,10)$. GIS'de en fazla iskemiye daha hassas olan ince barsaklar tutulmakla birlikte olgumuzda kolon tutulumu görülmüştür $(2,11)$. HSP'sı olan hastalarda ailevi Akdeniz ateşi (FMF) sıklığı belirgin artmış olup HSP ve ankilozan spondilit birlikteliği çok daha nadir olarak görülmektedir $(12,13)$.

Ankilozan spondilit genç erişkinlerde görülür. En sık başlangıç ve en sık görülen semptomu bel ağrısıdır. En erken radyolojik değişiklikler sakroiliyak eklemde görülür ve periferik eklemlerden en sık kalça eklemi tutulur. Ekstra artiküler olarak genellikle tekrarlayıc1, kısa süreli ve sorun yaratmayan akut ön üveit atakları (\%20) oluşur (4). Seyrek olarak aort kökünde inflamasyon sonucu aort yetersizliği ve ileti bozuklukları görülür $(14,4)$. Daha nadir olarak IgA nefropatisi de tanımlanmıştır. Hastaların yarısında GIS'de mikroskopik olarak inflamasyon saptanmasına rağmen klinik olarak genelde yakınma seyrektir (\%5-10) (4). Ankilozan spondilitli hastalarda ince ve kalın barsakları da içeren GIS'de iltihabi barsak rahatsızlıkları eşlik edebilir (14). Bu durum hastalarda karın ağrısı, ishal, kilo kaybı gibi şikayetlere neden olur.

Kore'de 2008 yllında Su Jun Kim ve arkadaşları HSP ve ankilozan spondilit birlikteliğini taşıyan bir olguyu paylaşmışlar ve her iki hastalı̆ı̆n patogenezinin benzerlik gösterdiği ve birbiriyle ilişkili olabileceğini vurgulamışlardır (14). Ankilozan 
spondilitte immun globülinlerden biri olan IgA ve akut faz göstergelerinde artış ve inflamatuvar bir histoloji saptanır (4). Yine 2003 yllında Izmir'de Turan ve ark. HSP, FMF ve seronegatif spondiloartropatili bir olgu bildirmişlerdir (12).

Sonuç olarak HSP düşünülen hastalar; karın ağrısı ve akut ateş atakları nedeniyle FMF açısından iyi sorgulanmalı, kalça ve bel ağrları, sabah sertliği gibi seronegatif spondiloartropati düşündüren belirtiler araştırılmalıdır. Hastaların takip ve tedavilerinde bu hastalıklar her zaman akılda tutulmalı ve göz ardı edilmemelidir.

\section{KAYNAKLAR}

1. Melikoğlu M. Vaskülitik Sendromlar. In: Yazıcı H, Melikoğlu M, Hamuryudan V, Sonsuz A. Ed: Cerrahpaşa Iç Hastalıkları Romatoloji Kitabı. Istanbul: Istanbul Tip Kitabevi 65-79.

2. Ergün M, Cindoruk M, Ünal S, et al. Erişkin başlangıçlı Henoch-Schönlein vasküliti: Üst gastrointestinal kanamanın nadir bir nedeni. Akademik Gastroenteroloji Dergisi 2011;10:74-6.

3. Gardner-Medwin JM, Dolezalova P, Cummins C, Southwood TR. Incidence of Henoch-Schönlein purpura, Kawasaki disease, and rare vasculitides in children of different ethnic origins. Lancet 2002;360:1197-202.

4. Yurdakul S. Seronegatif Spondiloartropatiler. In: Yazıcı H, Melikoğlu M, Hamuryudan V, Sonsuz A. Ed: Cerrahpaşa Iç Hastalıkları Romatoloji kitabı. Istanbul: Istanbul Tip Kitabevi 59-64.

5. Ozen S, Ruperto N, Dillon MJ, et al. EULAR/PReS endorsed consensus criteria for the classification of childhood vasculitides. Ann Rheum Dis 2006;65:936-41.

6. Ebert EC. Gastrointestinal manifestations of Henoch-Schönlein purpura. Dig Dis Sci 2008;53:2011-9.

7. Trapani S, Micheli A, Grisolia F, et al. Henoch-Schönlein purpura in childhood: epidemiological and clinical analysis of 150 cases over a 5-year period and review of literature. Semin Arthr Rheum 2005;35:143-53.
8. Blanco R, Martinez-Taboada VM, Rodriguez-Valverde V, et al. HenochSchönlein purpura in adulthood and childhood: two different expressions of the same syndrome. Arthritis Rheum 1997;40:859-64.

9. Lippl F, Huber W, Werner M, et al. Life-threatening gastrointestinal bleeding due to a jejunal lesion of Henoch-Schönlein purpura. Endoscopy 2001;33:811-3.

10. García-Porrúa C, Calviño MC, Llorca J, et al. Henoch-Schönlein purpura in children and adults: clinical differences in a defined population. Semin Arthritis Rheum 2002;32:149-56.

11. Sharma A, Wanchu A, Kalra N, et al. Successful treatment of severe gastrointestinal involvement in adult-onset Henoch-Schönlein purpura. Singapore Med J 2007;48:1047-50.

12. Turan Y, bayram KB, Özsüer D, et al. Henoch-Schönlein purpurası sonrası gelişen ailesel Akdeniz ateşi ve sınıflandırlamayan spondil artropatili bir olgu. Izmir Atatürk Eğitim Hastanesi Tip Dergisi 2003;6:29-32.

13. Doğanavşargil E. Sistemik Vaskülitler. In: Doğanavşargil E, Gümüşdiş G, Ed: Klinik Romatoloji El Kitabı. Izmir; Güven Kitabevi, 2003:381-471

14. Kim SJ, Lim TK, Kim YJ, et al. A case of ankylosing spondylitis in a patient with Henoch-Schönlein purpura. J Korea Rheum Assoc 2008;15:268-72. 